\title{
Touring Turtle Island: Fostering Leadership Capacity to Support First Nations, Métis, and Inuit Learners
}

\author{
Dawn C. Wallin \\ University of Manitoba \\ Sherry Peden \\ University College of the North
}

\begin{abstract}
This paper reports on findings from a research study that examined the design, delivery, and effects of a graduate level summer institute, the aim of which was to foster the capacity of educational leaders to support First Nations, Métis, and Inuit (FNMI) learners. Our study is conceptually framed using elements of critical race and Whiteness theory, and red pedagogy/culturally relevant pedagogy. We designed the institute and our methods around Kirkness's and Barnhardt's (1991) 4 R's of success in higher education environments: relevance, reciprocity, responsibility, and respect. Data for the study were gathered using a qualitative, inquiry-based methodology, and articulated using Indigenous storywork and story. The primary data sources included online surveys and sharing circles conducted with past students of the course. Findings suggest that the summer institute helped to disrupt colonial assumptions; increase respect for Aboriginal knowledges, values, and experiences; offer relevance to educators who were able to use the learnings of the course in their own professional contexts; affirm the need for reciprocity between schools and FNMI families; and develop educational leaders' sense of responsibility to ensure FNMI learners are supported in the public school system.
\end{abstract}

Keywords: Indigenous education; educational leadership; educational administration; critical race theory; Whiteness theory; red pedagogy; culturally relevant pedagogy; teacher education 


\section{Touring Turtle Island: Fostering Leadership Capacity to Support First Nations, Métis, and Inuit Learners}

This paper culminates out of a journey of relationship building, respect for alternate world views, responsibility to and for the learning of others, and reciprocity between colleagues, teachers, and friends (Kirkness \& Barnhardt, 1991). Our story grows out of the relationship that two rather unlikely compadres formed with each other in 2008. One of us, Sherry, became a doctoral student at the University of Manitoba as part of an innovative program initiative entitled the PhD Studies for Aboriginal Scholars (PSAS) program. This program was the brainchild of Dr. Verna Kirkness, a renowned Aboriginal scholar, and was an attempt to recruit Aboriginal scholars into $\mathrm{PhD}$ programs across campus underpinned by social, financial, and academic support networks. Given that Sherry's academic interest and professional experience as an educator and faculty member at Brandon University was in educational administration, she chose as her advisor the second of us, Dawn, whose work centered in educational administration, rural education, and gender issues.

Bogden and Biklen (2007) suggest that researchers must "acknowledge that no matter how hard you try, you cannot divorce your research and writing from your past experiences, who you are, what you believe and what you value” (p. 38). Sherry defines her identity as an Anishanabe woman "from the bush" in Manitoba. Dawn defines her identity as a Western Saskatchewan "farm kid.” Both of us define ourselves as feminists. Sherry's Aboriginal view of knowledge and learning is holistic, adaptable, dynamic, and relational (Battiste, 2002; St. Denis, 2007). Dawn's training and socialization into educational administration has been framed by notions of learning as linear, discrete, and hierarchical, defined often as Eurocentric education (Battiste, 2002; Chamberlain, 2000). Needless to say, our first meeting was fraught with the tensions felt by a new student and the dazzling academic rhetoric spouted by an advisor. Eventually, however, the common touchstones of language and humour understood by people who prefer to be outside of the city limits began to frame our communication together. At one point in our discussion, Dawn's rural roots (or maybe her feminist ones) came to the fore as she said that "we were entering a journey as advisor and student, and unlike a marriage, neither one of us could bail out when the going got tough." This comment dispelled the pretentiousness so often a part of the academic landscape, and began to cement a relationship that has stood the tests of the colonizing realities of the Academy, the angst of world view clashes, and the building of a collegial friendship that has at its heart a common interest in supporting First Nations, Métis, and Inuit learners.

In this paper, we discuss the results of an inquiry-based research project underpinned by Indigenous pedagogic and research principles that we conducted through a summer institute we designed and co-taught. We designed the institute and our methods around Kirkness's and Barnhardt's (1991) 4 R's of success in higher education environments: relevance, reciprocity, responsibility, and respect. The institute was targeted to public school leaders to disrupt their Western conceptualizations of education and foster their capacity to support First Nations, Métis, and Inuit (FNMI) learners.

We have chosen to use a decolonized manner of expression that utilizes a story approach similar to others who integrate Aboriginal perspectives and experiences by 
connecting story to academic theory (Archibald, 2008; Wilson, 2008; Young, 2006). We have conceptualized our work within critical race/Whiteness theory, and red pedagogy/culturally responsive education. The aim of the research involves the critique and transformation of social, political, cultural, economic, ethnic, and gender structures that have historically constrained and exploited Aboriginal people, and continue, to do so. This research is part of the journey towards celebrating voice and culture, and legitimating Aboriginal scholarship.

\section{Background}

First Nations, Métis, and Inuit (FNMI) students often encounter debilitating challenges in public school classrooms when cultural and racial issues go unacknowledged by teachers, administrators, or classmates. Manitoba has 15\% of Canada's FNMI population, of which $48 \%$ are of school age, yet only $56 \%$ compared to $77 \%$ non-FNMI students are graduating from public schools (Statistics Canada, 2006). Almost 20 years ago, in 1996, the Royal Commission on Aboriginal Peoples (RCAP) recognized that although there were a number of sincere efforts undertaken beginning in the 1970's to improve the success rates of FNMI students, the Commission noted, "too many youth [still] do not complete high school, they do not have the skills for employment and they do not have the language and cultural knowledge of their people” ( p. 434).

Unfortunately, not much has changed, as scholars continue to speak about the huge discrepancies in attendance and achievement rates of FNMI students (Donald, 2009; Ireland, 2009; St. Denis, 2010; Williams \& Tanaka, 2007). Race and racism is not only present in our public schools, but also it can be considered one of the most insidious elements that detract from the educational success of FNMI students (Ireland, 2009; St. Denis \& Schick, 2003; St. Denis, 2007, 2010). Although Aboriginal scholars have written extensively on the colonizing effects of Western Canadian teacher education programs, there remains a huge gap between what is advocated as a more responsive teacher education program and FNMI students’ experiences in schools.

In an attempt to improve the situation for FNMI learners, in 2008 the Manitoba Minister of Education mandated that faculties of Education across the province restructure teacher education programs to include a compulsory course on Aboriginal perspectives, histories, and pedagogies. FNMI mobility patterns coupled with FNMI population growth rates indicate that more and more FNMI students are attending provincially controlled schools. These systems are typically staffed by high numbers of educators and administrators who represent the White Eurocentric demographic and world view.

Sherry's mixed methods dissertation research explored the perceived impact of the mandate on the teacher candidates who completed the course at Brandon University's Faculty of Education during the 2008-2010 academic terms (Peden, 2011). An initial resistance to course content existed, causing angst for both students and herself as the Aboriginal instructor as students engaged with contentious issues, the deconstruction of privilege and examples of institutionalized racism within the educational system. These kinds of pursuits in the university classroom are often fraught with difficulty for both the teacher candidates and the faculty because such activities necessitate that, in the words of 
Vaught and Castagno (2008), "white teachers be able to recognize that white racial power permeates every institution and that race and racism inform low student achievement" (p. 101). People must scrutinize all aspects of their lives, past experiences, and fundamental beliefs. Upon doing so, they often demonstrate responses ranging from resistance and anger (Aveling, 2006; St. Denis \& Schick, 2003; Vaught \& Castagno, 2008; Whitehead, 2007), to White guilt, which can move into White paralysis (Thompson, 2003). They may also engage a variety of social and ideological tools to resist their movement towards less racist paradigms and structures (Aveling, 2006; St. Denis \& Schick, 2003).

Fortunately, more positive attitudes, regarding FNMI content, world views, pedagogies, and people, developed over the duration of the course, which were similar to Donald's (2009) interactions with preservice teachers at the University of Alberta: Students generally recognized that "the formal [education] systems have marginalized Aboriginal peoples and their knowledge systems in the past and they expressed a desire to critique accepted teaching practices and discuss new ideas and approaches" (p. 6). Unfortunately, Sherry found that once teacher candidates moved into the school system, their desire to implement their learnings was often challenged by racist attitudes and practices, particularly in schools where administrators did not foster FNMI education. This finding coincided with that of Kanu (2005) who asked practicing teachers in Manitoba to identify the barriers or obstacles that existed about integrating Aboriginal culture and world views into the curriculum. She found that "the overwhelming response was the racist, stereotypical images of Aboriginal people that were held by nonAboriginal colleagues and students” (Kanu, 2005, p. 56). Sherry concluded her study by suggesting that the mandate and work of the Aboriginal Perspectives course is necessary work, but it must be sustained across the entire educational system and across the career stages of all educators in order to change the social attitudes that continue to dominate in schools. Particularly important was the need for principals to give overt support Aboriginal knowledges, content, and pedagogies, as well as the teachers who now held this understanding.

As Sherry worked through her dissertation research, the two of us engaged in discussions that lasted until the wee hours of the morning, strategic planning on how the study would be best designed and enacted, and an incredible amount of theoretical and embodied learning. Although Dawn was well versed in the educational leadership literature, she had much to learn about decolonization, Aboriginal epistemologies, and the experiences of Aboriginal peoples in Canada. She had to deconstruct her own assumptions and values, recognize the White privilege she held, and work through her feelings of White guilt in order to become an effective ally. During this time, on a number of occasions, we lived the clashes of our world views in debates, in our ways of being and thinking, and even in a good old-fashioned yelling match or two.

As an Aboriginal scholar and mother, Sherry did not need to be convinced of the urgent need for adapting or changing systems or curricula to meet the needs of Aboriginal learners better. Instead, she was continually frustrated by the reality that systemic change has been publicly advocated by Aboriginal leaders, parents, and scholars since the National Indian Brotherhood's 1972 response to the White Paper of 1969, but FNMI learners continue to struggle. Although there is a plethora of rhetoric on educational accountability and standards-based reform, Johnson (2002) has noted, "There is an 
absence of meaningful discussion on how to achieve equitable outcomes that do not unfairly penalize the most under-served students” (p. 4). Though the literature taught Sherry how to, in Freire's (1970) words, "name the world," the findings of her study caused sorrow and frustration. On one particularly depressing evening, while we were running through the results of her research, Sherry threw up her hands and uttered, "None of this is going to make a difference if we can't get through to those principals.” Though Dawn made no promises in the moment, she knew that summer course planning was just beginning at the University of Manitoba. She pitched an idea to her educational administration colleagues that had started to grow from the seeds of Sherry's research. Within a week, Dawn called Sherry to say that she had been granted permission to design a summer institute to be co-taught with Dawn that would target public school principals to develop their capacity to support FNMI learners. The summer institute was born.

In 2011, we co-taught our first summer institute to what we believed was a resounding success. In winter 2013, we conducted an inquiry research project with former students, gathering feedback on the design and delivery of the institute, and potential recommendations for future offerings. We wished to study how we could best implement the content, pedagogy, and values associated with an Aboriginal world view while being respectful of the world view held by the majority of students who were not Aboriginal. We deliberately designed the course to disrupt assumptions; to be experiential in format; to decentre ourselves as "the experts;" to value students' own knowledges and experiences; and to center Aboriginal educators, scholars, elders, parents, and community members as key contributors to the educative process. This paper reflects the results of that inquiry study.

\section{Teacher Education}

On June 1, 2010, the Association of Canadian Deans of Education signed an Accord on Indigenous Education that identifies goals related to respectful and welcoming learning environments, respectful and inclusive curricula, culturally responsive pedagogies, mechanisms for valuing and promoting Indigeneity in education, affirming and revitalizing Indigenous languages, Indigenous educational leadership, non-Indigenous learners and Indigeneity, and culturally respectful Indigenous research

Although the Accord provides support and impetus for change, Schick and St. Denis (2005) discuss the pervasive "whiteness norm” that exists in faculties and teaching staffs in most areas of southern prairie schools and faculties of education. In their view, when dominant cultural practices and standards prevail, enormous privilege is assumed by those students and faculty members whose "histories, ethnic backgrounds, social practices, family systems and knowledge exist in the institutions” (Schick \& St. Denis, 2005, p. 300). This has created organizational, pedagogical, and instructional challenges for the design and implementation of Aboriginal education courses. Instead, what occurs is what Battiste (2004) calls the "add and stir" approach where students are taught about "beads and bannock" that serves to exoticize Aboriginal people while doing little to advance Aboriginal knowledge, world views, and epistemologies.

To date, however, the promotion of Indigenous education and culturally relevant pedagogy has remained primarily at the level of teacher education, and not leadership 
education. There has been no formalized movement in any university in Canada or by provincial governments to ensure Indigenous education principles are embedded in school leadership programs and/or administrative certification, except as advocated by individual faculty members, introductions of special courses, or requested by individual students. Although there exists a plethora of literature on principal preparation and leadership development, and a growing literature base on Indigenous leadership, there is only a limited literature base that advocates for school leadership preparation in the area of Indigenous education and/or coursework and leadership practices underpinned by Indigenous principles (Ottmann, 2010). With our work, we hope to make the case that teacher and leadership preparation programs must prepare school leaders not only to work with Indigenous students, teachers, and communities, but also to equip them with the tools necessary to recognize the White privilege upon which the public education system is based, and to use their influential roles to aid in the process of decolonizing education.

The challenge in teacher education (and arguably in leadership education) begins with the tensions generated around what scholars note as "jagged world views colliding" (Little Bear; 2000; Stewart, 2009). Divergence amongst the world views occurs around the concepts of what constitutes education, the curricula, and pedagogies. When students are provided with learning opportunities that confront their basic assumptions about knowledge, education, and society in a respectful manner, they typically begin the process of changing how they view knowledge, academic success, the role of education, and the relationship between policies and praxis in education. This kind of pedagogy, that of building what St. Denis (2007) calls, "educational allies," takes a great deal of time and emotional effort because of the sensitive nature of the content and processes that challenge students to understand how racialization has historically, politically, and legally affected Aboriginal people in Canada. It is doubly hard to do this work when the instructor who represents the "Other" as an Aboriginal person in a room full of (mostly) White students, challenges the beliefs and systems in which students have been successful. We believed that team teaching our summer institute would allow educational leaders to work through this jagged world collision as we modeled it as team instructors.

White stream educators are typically sympathetic to the idea of inequity, and to the individual who has been treated unjustly, but they ignore or minimize the social constructions that cause structural inequity or racism within our institutions (Guinier \& Torres, 2002). Because these individuals do not recognize the colonial assumptions underpinning their world view, many are ignorant of the fact that organizational structures often subtly prohibit the educational success of FNMI students. Instead, they want to "help" or "fix" FNMI students so that they better fit a corrupt system. Therefore, our goal in the leadership training of these educators was to ensure that students had to confront these social constructions and recognize their own role in perpetuating systemic inequity.

Levine-Radsky (2000) noted that educators can often be classified according to the following three value systems regarding racism and Whiteness: (a) traditional teachers who deny or dismiss the relationship between social organizations such as school and racism; (b) progressive teachers who are willing to explore the relationships between schools and racism; and (c) ambivalent teachers who are conflicted about their 
stance on issues, and therefore, express contradictory beliefs about racism and schools. Many educators resist the idea that they may need to rethink the system, since that entire system is premised upon, and perpetuates, their own assumptions. Consequently, the educational philosophy and beliefs they bring (consciously or subconsciously) to their teaching or leadership practices often work in direct contrast to the educational needs of Aboriginal students whose world views may be entirely different. It was our intent to overtly problematize these realities and discuss how leadership could be envisioned to support Aboriginal learners more effectively.

We set the stage at the beginning of the summer institute by overtly articulating that we intended to disrupt student assumptions, that no question was politically incorrect to ask, and that we were open to debate, disagreement, and tension. We told students that they would be made to feel uncomfortable, and that they may have to work through feelings of anger, betrayal, and/or guilt, but that this was a normal part of an educative process where people's values and assumptions were challenged. Dawn articulated her own movement through these kinds of feelings; the focus turned to what it meant to be an ally, and how to appreciate and respect difference in ways that were not patronizing and/or perpetuating White privilege.

Morrison, Robbins, and Rose (2008) demonstrated that teachers were able to incorporate pedagogies that supported high academic expectations and culturally congruent understanding into everyday teaching, but they fell short in developing the socio-political consciousness that is said to be a capstone for culturally relevant pedagogy. It is in changing the attitudes and developing the critical consciousness that students are provided with the tools to "transform their lives and ultimately the conduct of society" (p. 443). Lowenstein (2009) refers to the lack of capacity of teachers to meet the needs of Aboriginal students in curricular and pedagogic ways as being characteristic of the demographic discrepancy between the socio-cultural characteristics and prior experiences of the majority of teachers and the students whom they teach. We need to devise ways to employ what Battiste, George, and Anuik (2009) call "two-eyed seeing," where Indigenous or Aboriginal knowledge is normalized into the curriculum, school practices, and school culture so that both ways of learning are validated and valued for the success of all students.

In the case of our summer institute, we opened and closed our time together with sharing circles facilitated by elders. To demonstrate respect for individuals, Mother Earth, and the Creator, we conducted each day with the cultural protocols. We presented students with political and academic resources written by Aboriginal scholars. Our days were organized almost entirely off campus, in venues and communities where First Nation, Métis, and/or Inuit people facilitated the learning experiences of each visit. We visited centers such as the Manitoba Treaty Relations Commission, the Manitoba Truth and Reconciliation Commission, the Manitoba Métis Federation, the Manitoba First Nations Education Resource Centre, and the Manitoba Indigenous Cultural Education Centre, where educators could access resources and the wisdom of the elders and/or professionals who demonstrated their commitment to FNMI students and a willingness to work together for change. Students car-pooled to First Nations communities like Fisher River Cree Nation in order to view the positive initiatives being facilitated in First Nations schools, and they attended a retreat at Sagkeeng First Nations with Elder Dave 
Courchaine to learn about Spirit. At all times, they were presented with a sense of humour, a generosity of spirit, a depth of knowledge and understanding, and a relational openness that continually dismantled their preconceptions of Aboriginal knowledges, experiences, and contexts. Our assessment of students was based upon personal reflection pieces that demonstrated their growth over the duration of the course, a group presentation related to a topic of concern, and an action plan to support FNMI learners that they could implement in their schools.

\section{Theoretical Background}

\section{Critical Race Theory}

Critical race theory (CRT) has roots in critical legal studies (Bell, 1991; Delgado, 1995; Crenshaw, Gotander, Peller, \& Thomas, 1995) focusing on the over-representation of marginalized people in the criminal justice system. CRT identifies race as a factor in social relations that privilege Whiteness and is constructed on three tenets (a) the recognition that racism has social effects and that all oppressions are interlocking, (b) the critique of ideologies that relate to liberalism and meritocracy, and (c) the problematizing of the voices of those who have been marginalized by society (Dei, 1996; Kailin, 1994; Thompson, 2003). Critical race scholars believe that scholarship cannot be objective or neutral; they advocate for alternative methodologies such as narrative and literary techniques that challenge traditional paradigms and make way for excluded voices.

In relation to education, CRT focuses on naming racism and investigating the effects of racism on educational achievement at an individual and communal level by addressing the philosophies of meritocracy and the hegemonic practices involved with White privilege in school systems. St. Denis and Schick (2003) emphasized that "by claiming that 'we are all part of the same human race' and that the 'color of a person's skin is invisible', students whitewash the daily advantage of white privilege” (p. 55). The claiming of color blindness negates the realities of those who occupy the minority and often-marginalized position (Brown, 1995). Ultimately, according to Ladson-Billings (2005), CRT serves "as a new analytic rubric for considering difference and inequity using multiple methodologies - story, voice, metaphor, analogy, critical social science, feminism and postmodernism” ( p. 9).

\section{Whiteness Theory}

Whiteness theory refines CRT and describes how race plays a role in the inequities faced by minoritized students, which is perpetuated by (primarily White) educators (Dlamni, 2002; Harris, 1993). Picower (2009) posits that racism is a normal, inherent feature of Western society; therefore, teacher educators must employ methods that will assist teacher candidates in developing a socio-political consciousness to become educators that are more effective. Whiteness is not just about skin color, but also, as Shome (1999) points out, about "the discursive practices that because of colonialism and neo-colonialism, privilege and sustain the global dominance of White imperial powers and Eurocentric worldviews” (p. 108). Langer (1997) suggests that by engaging teacher candidates in the articulation of Whiteness as a collective or societal state, teacher educators can potentially assist future teachers to move to a state of mindfulness that involves the creation of new categories, being open to new information, and being aware 
of more than one perspective. Langer contends that the mindful state is a proactive state as opposed to the state of mindlessness whereby the habitual use of preordained scripts, norms, and stereotypes simply perpetuates or maintains the status quo.

St. Denis (2007) stated that teacher education ought to utilize an approach whereby coalitions are created among all educators such that we work "to uncover and understand how racism and the normalizing and naturalizing of White superiority continues unabated in our schools and communities” (p. 1088). Teacher candidates should study Whiteness to understand and deconstruct how racism and privilege continue to play a role in education (Aveling, 2006; Levine-Radsky, 2000; Picower, 2009; Terwilleger, 2010) in order to disrupt the norms of power and ideology that privilege some and marginalize others.

\section{Red Pedagogy}

Red pedagogy is a pedagogy that focuses upon re-imagining the social and intellectual spaces of what it means to be an Indian in North America today (Grande, 2008, p. 241). It is a revolutionary form of pedagogy with roots in critical pedagogy (Freire, 2003; Kincheloe, 2003; McLaren, 2003). Red pedagogues are involved in a form of decolonized pedagogy that "questions how knowledge is related to the processes of colonization,” writes Grande (2004, p. 56). Red pedagogues are able to analyze critically the intersecting systems that have historically constrained Indigenous people and develop the tools to navigate those systems. Grande (2008) asserts that red pedagogues need both the knowledge of how the oppressor works and the skills to dismantle and rebuild culturally responsive systems.

In her view, red pedagogy is based upon the following seven precepts:

1. It is inherently political, cultural, spiritual, and intellectual.

2. It is rooted in Indigenous knowledge and praxis.

3. It is informed by critical theories of education.

4. It promotes an education for decolonization while not making claims of political neutrality but engages dialogue and inquiry related to capitalisticimperialistic matters.

5. It interrogates both democracy and Indigenous sovereignty.

6. It cultivates the practice of collective agency by creating transnational and transcultural coalitions among Indigenous people and others committed to developing a more equitable society.

7. It is grounded in hope that trusts the understandings and beliefs of the ancestors. (Grande, 2008, p. 250)

Red pedagogy is a hopeful discourse premised upon building coalitions among all levels of educators to disrupt the colonial and neo-colonial manifestations that harm our collective future. 


\section{Culturally Relevant Pedagogy}

Culturally relevant pedagogy (Ladson-Billings, 1995) includes practices and strategies that utilize and build upon the intellectual, social, emotional, and political dimensions of students by using their cultural referents to develop knowledge, skills, and attitudes. Teachers who practice culturally relevant pedagogy: hold high expectations for the academic abilities of students; are willing to nurture and support cultural competence; and develop students' socio-political or critical consciousness. Gay (2000) suggests that culturally responsive teaching is a validating pedagogy that teaches to and with the strengths of students by utilizing their prior experience, cultural knowledge and learning/performance styles to make learning more effective. Culturally responsive teaching includes differentiated instruction; incorporates multicultural resources, information, and perspectives into subject and skill areas; provides relevance by integrating school learning with the socio-cultural reality of students, and acknowledges the legitimacy of cultural languages and perspectives. Teachers who practice culturally relevant education become part of the community at large, rather than acting as expert in an isolated classroom. Pewewardy and Hammer (2003) suggest that in order to become culturally responsive, educators must develop culturally literacy; conduct a self-reflective analysis of attitudes and beliefs; develop caring, inclusive, and trusting classroom environments; respect all kinds of diversity, and; transform the curriculum to develop meaning and relevance for all students. Culturally relevant schooling embraces a holistic approach to schooling and does not view curriculum and teaching as the totality of education, but takes into account school policy, student expectations, standards, teacher expectations, and community involvement.

\section{Methodology}

McNiff and Whitehead (2006) state that an "agent [researcher] is someone who brings about change, and whose achievements can be judged in terms of their own values and objectives, whether or not we assess these in terms of external criteria as well" (p. 29). As educators and researchers, we conducted this study because we wanted to know whether our summer institute helped foster changes in the attitudes of in-service teachers and administrators such that they would go back into their schools and work towards systems change. We also wanted to elicit from students feedback on the course so that we could strengthen it the next time we offered the institute.

We were fortunate in that neither of us were any longer in a position of power visà-vis the past students in our faculty roles, and therefore, we were able to gain ethics consent to contact students via email through a third party and have them contact us directly if they were interested in participating. Unfortunately, many of the students had graduated from their programs after the summer institute, so we were unsure if the contact emails we used to request participation remained valid. Because former students were dispersed across Manitoba and in other provinces, we decided to utilize two methods for collecting data: an online survey on Fluid Survey and sharing circles for any students who could be available to meet with us.

Because we wanted to underpin our research by Indigenous research principles, we grounded our questions in Kirkness's and Barnhardt's (1991) 4R's of success in 
higher education learning environments. Participants were asked to discuss the extent to which the 4R's - relevance, reciprocity, responsibility, and respect-were evident in the design and delivery of the course. We asked them (a) to what extent they had been able to incorporate the content, resources, strategies, and/or experiential learning opportunities of the summer institute into their own teaching/leadership contexts, and what supports and/or challenges affected their ability to do so; (b) what learnings and experiences had helped them in their professional roles as they worked to support FNMI learners; (c) what more they would have liked to learn; and (d) what supports they needed to help their professional growth, and what recommendations they had to improve the course. We analyzed the data using a constant comparative method. Out of the 20 students in the course, four individuals elected to complete the online survey, and five individuals came together to be part of a sharing circle. The findings below provide the depth of information we received from both methods.

\section{Findings}

\section{Important Learnings}

Participants gleaned a number of important learnings from the course. The first was an understanding of how history shapes the perspectives of students and parents. Many talked about having no real knowledge about the treaty relationship between First Nations peoples and the Crown, or the political and social differences between First Nations, Métis, and Inuit peoples. They spoke of the need for cultural teachings to be represented in curricula in meaningful ways that valued the experiences and knowledge of Aboriginal peoples, and about coming to terms with how integral relationality was in their own learning and working with FNMI students. Many had never considered how cultural or environmental shock impacted upon FNMI children who moved between their home communities and city public schools. They came to value place-based and experiential education given their experiences in the summer institute. As one participant mentioned,

It doesn't matter how many times you read it. But you go in and you talk to people who have experienced those types of situations and their reasons why. Someone who is an elder or someone who has that experience in life tends to be able to articulate more...that whole part in my position was invaluable to me. It's just given me a greater understanding of where those kids are coming from. (participant, sharing circle, 2013)

Finally, participants spoke of the need for authentic dialogue and challenging the assumptions of others who remained "stuck" in racist or deficit thinking.

\section{Culturally Relevant Pedagogy}

Participants raved about their engagement in the experiential learning opportunities of the course. As one individual claimed,

It's been one of the more positive experiences I've had in terms of taking a class because it wasn't sitting down for 10 days in the university and listening to someone go on and doing a project and all the rest of that kind of stuff. It was 
getting out, and going to all those different places. And finding out that, yeah, there are people there, and this is what they do. (participant, sharing circle, 2013)

Participants discussed their growing comfort in asking difficult questions because of the inclusive environment that was created where multiple perspectives and world views were respected, and where student voice was encouraged. They enjoyed the use of sharing circles where each individual was acknowledged, the stories that engaged them in discussions, and the wisdom presented by the elders. Interestingly, all participants mentioned the value of the road trips, during which they were able to dialogue with other students away from the ears of the instructors. Finally, they appreciated what they termed the "tag-team instruction" by two instructors who represented very different world views, who modeled what it could be like to work together to improve Aboriginal education, and who intentionally troubled the notion of the teacher as "expert." This finding reinforced our own hunches, since it had been evident to us throughout the course that students had differing comfort levels in relation to each of us.

\section{Challenging Assumptions}

Participants acknowledged their discomfort with having their assumptions about Aboriginal knowledges and experiences challenged. The majority of students had never visited a First Nations community or spent time in areas of Winnipeg in which many of the venues we visited were situated. Many suggested the course was valuable because they were "forced" to go places that "I would never go on my own" (survey participant, 2013), which had helped them to recognize their own constructions of privilege and fear. They were able to challenge their sense of political correctness as misconceptions, racist ideas, and White privilege was deconstructed. They spoke of their misconceptions of the treaties and a growing awareness of how history has shaped current practice and experience. They discussed the rhetoric around First Nations education in the province that appeared altruistic, but was often underlain by the convergence of secondary motives of interest. What challenged many of the participants were the successful, articulate, and forward thinking elders and Aboriginal professionals who time and time again invited the students to work with them towards change. Rather than the bitterness that could be expected to be present given the historical experiences of Aboriginal peoples, these individuals, although acknowledging their tragic past, moved forward in hope for a better future. As one participant noted:

Everybody had a story. And I think the thing that impressed me most was that nobody was saying, "Poor me." It was all, "Here’s what it is." No one was looking to make excuses or blame anybody, but it was the talking....But it's that whole thing of what lies beneath the surface and what you can find. Everybody that we talked to was sharing the stories so that helped me put things together. And gave more of an insight as to who Aboriginal people are versus what we see...I shouldn't say what we see...I mean what we perceive, and what we see on TV. (participant, sharing circle, 2013)

Finally, individuals started to challenge their own lack of knowledge on what was going on in their school systems related to FNMI learners. They began to question where provincial grant money designated for FNMI students actually went. They began to 
consider why, how, and for what purpose information is collected regarding FNMI students. And they began to question the reasons why some FNMI students were not engaging in school, rather than prejudging causes based upon stereotypes of uncaring parents, lack of ability, or involvement in negative lifestyles. In short, they began questioning why they were not involving themselves in finding out causes and solutions for supporting students and families.

\section{Instructors}

Although some researchers would question our findings on this topic given that the participants were talking to us about our instruction, we think these comments represent what an ideal instructional situation might entail. As mentioned earlier, students appreciated the tag-team approach to instruction that we embodied. One woman encapsulated her rationale by stating:

I like [that] there was two of you because there was always two people to talk to and different ways of looking at things, which is the way that I think most information should be presented. And different life experiences too... when the content is so intense and can be so personal and sensitive; it's nice to have more than one facilitator to be able to take your questions to. I think it's pretty important. (participant, sharing circle, 2013)

Participants valued our different life experiences and world views, and that we modeled mutual respect for each other and for our students. They appreciated that we shared our own fallibilities, that we decentred class expertise and control, and that we positioned ourselves as learners along with the students. They noted that we demonstrated positive collaboration with each other and with students that we supported and built on each other's input, and that we shared course decision making with students. Finally, they spoke of how they valued the very different but supportive feedback we provided to students. Students handed in two copies for every assignment, and we provided individual written feedback separately. We then came together as a team to discuss the work, and provide a final grade. This was an intense and lengthy process, but it also allowed us to respond based on our own strengths and understandings of the work. Though both of us wrote reams of comments on each paper, students noted that Sherry tended to focus more on the Aboriginal content and/or experiences of Aboriginal peoples, and Dawn focused on the scholarship and students' development as academic writers.

\section{Relevance}

Participants had no trouble articulating the ways in which the course was relevant to their professional roles and growth. They discussed how they now incorporated many of the course resources into their own classrooms, and how some of the ideas and experiences had helped them to initiate programs for parents and students. They spoke about their developing self-awareness and cultural understanding, and how, consequently, they were able to improve their professional practice. They recognized the need to develop local community and cultural understanding, and were able to link the knowledge they had obtained from course guests to current student/family concerns in their own schools. Their experiences of meeting course guests or of visiting First Nations communities helped a number of participants build links to families and students who 
now could connect a place or a name to their lives. This was mentioned by a participant who had the following experience subsequent to the course:

[One of the Aboriginal students who was having trouble in school] was from where [a student in the course] was from...So I told him, "Oh, I took a course with someone from there." And he knew her, right? And then I got the picture of her. And, I kept calling her [the wrong name]. (Laughter). So he'd keep correcting me. And then, he'd update me. So he'd tell me, “Well, I don't think she's on Council anymore, and she worked in a store, or owned a store-so just that little connection. And we've had students from Peguis. I was able to say, “Oh, I drove through it on the way to Fisher River. So they're always amazed that I know where it is. And so, I think those were big. (Participant, sharing circle, 2013)

Finally, they also acknowledged with a sense of pride that they knew some of the course guests who they saw surfacing as guests in their school, on Twitter, or in the media.

\section{Reciprocity}

In terms of reciprocity, participants suggested that their growing self-awareness helped them to build authentic relationships with parents and students. Getting to know people in the course helped them access resources and create networks for future opportunities. The course allowed students to take back information to their communities and school systems, and emphasized open communication. Finally, participants mentioned that they appreciated the reciprocity between instructors and students in course decision making.

\section{Respect}

Participants mentioned that their growing self-awareness prompted greater respect for families and students as they came to understand lived experiences and socio-cultural realities. They noted their respect for the resilience and strength of Aboriginal peoples and the accomplishments of course guests. As one man suggested,

The visit to Fisher River was a great one. ... Turtle Lodge as well. Getting down, and talking directly to people and having them answer your questions. And even Teddy Fontaine...his experiences and things like that. It just became something really real. You talk about the highs and the lows that we had, and you see what people are doing and what can happen. (Participant, sharing circle, 2013)

In course discussions, students developed respect for each other as they learned the extent to which individuals in the course cared for and desired to work towards improving the educational circumstances for FNMI learners. They also spoke of the mutual respect modeled between instructors, and between instructors and students.

\section{Responsibility}

The course fostered a sense of sociopolitical responsibility within students to share their knowledge and develop programs to support parents and community. They began to take responsibility for clarifying misinformation and the misassumptions of colleagues. They felt they needed to focus more on the importance of treaty education to 
provide more culturally relevant programming and enrichment. Perhaps most importantly, they felt a strong sense of responsibility to avert the continuing tragedy of students who "fall through the cracks" of our school systems:

The frustrating piece of the kids I teach...my strongest kids, the top 10\%, I'll bet you $70-80 \%$ of those are Aboriginal. They are so smart; they have so much ability..., but they're not coming to school. They don't show up, they get into attendance trouble, they miss some of the topics....Taking the course, I've learned more about the background and where they're coming from and the history, and their family, and even the timelines of residential schools and really how it's only a generation or two removed if that. But the influence and the repercussions are first hand right now.... And, you just know they could do so much. So, I think 'OK, what can I do?' I know a little bit, I don’t know a lot, but here are some resources... what can I still do? How can I still help them be successful.... What can we do as a school, as a teacher, what can we do? (Participant, sharing circle, 2013)

Comments such as this emphasize the emotional impact of the course almost two years after its offering. Though the sorrow of the man in question is clear, what is gratifying is the level of responsibility he feels to do more for the struggling FNMI learners in his school.

\section{Support and Challenges for Enactment}

Participants mentioned a number of challenges facing them as they went back into their schools hoping to effect change. They discussed the students who continued to "fall through the cracks," the levels of alienation felt by students, and the intergenerational effects of colonization that continue to impact the lives of students and families. They also spoke of lack of staff or community support for their efforts, a lack of financial support, or the misuse of targeted funding, lack of staff representation, and unsupportive administrations that stymied efforts or couched resistance in rhetoric versus real support. Fortunately, a number of supports were also mentioned. These included the resources available from the course and working with colleagues who inspire and support students and programs.

Four of the participants spoke of programs or initiatives they had been able to implement that created better conditions for FNMI learners. These included the development of extra-curricular options and supports for students who might be affected by poverty, travel, and/or time commitments; targeted staffing initiatives to increase the representation of Aboriginal educators in the school; more supportive intake procedures for students moving into the school from First Nations communities; and the institution of a Native Studies program in collaboration between teachers and the Aboriginal liaison to the community. They also discussed becoming more creative with targeted provincial funding for FNMI learners, and looking for proposal funding opportunities that could support their efforts.

\section{Conclusion}


Aboriginal education is based upon relationships (Battiste, 2000; Kirkness \& Barnhardt, 1991). Teacher educators must model how to develop and nurture respectful, trusting relationships with students given that they are asking students to question their value systems, privilege, and unconscious power as teachers and educational leaders. To do so, often requires teacher/leader educators to put themselves into vulnerable and public spaces, and decentre their role as "expert" within a system legitimates their world views and experiences. We believe our findings provide evidence that we were able to do this effectively within the confines of our summer institute.

One of the recommendations for the course was to make it a regular offering that was mandatory for principal certification. In our second iteration of the institute in 2013, we were able to have the course granted credit towards administrative certification in the province. Two students indicated that it would be nice to have a "Part 2" so that they could immerse themselves even more deeply into topics. Participants also recommended that we continue to offer the experiential learning opportunities and encourage the inclusive, open dialogue. They enjoyed the relatively small class size, but found it difficult to balance the readings with the daily experiences, assignments, and the emotional stress caused by the disruptions of their assumptions. They encouraged us to create developmental projects and assignments, to provide readings in advance, and to provide alternatives to the group presentations that were conducted at the end of the course that became anti-climactic given the intensity of the course.

In actuality, our class size burst to full enrolment of 35 students in 2013. We had to turn away a number of students because word had spread about the value of the 2011 course and because we opened the course to students in other graduate programs in the province. We changed the format to include a Saturday class in June to set out course expectations and provide readings in advance (although we recognized quickly that the educators in the course were so busy with end of year responsibilities that very few of them completed their readings prior to the course). We also turned the group presentation into a project-based carousel activity where groups had only 5 minutes to introduce their projects, but also had time to do a gallery walk and engage with each other in dialogue about their work. We hope to showcase these projects and encourage students to showcase them at this year's annual Shawane Dagosiwin conference organized by the Aboriginal Education Research Forum with Manitoba Education. Because we believe in the value of the action plan, we kept the assignment, but we split it into two parts to foster developmental learning. The first part consisted of the rationale for the plan, a general outline, and the literature review. The second part included the plan's goals and how to achieve these goals within the students' work contexts.

The findings of our study affirmed the need for preparation program research to utilize critical race (Ladson-Billings, 2005) and Whiteness theories (Picower, 2009) as lenses through which to examine educational practice. Teachers and school leaders who participated in the institute became more conscious of the racism and White privilege embedded in the Manitoba public system, and the ways in which those constructs worked to deter the educational success of FNMI learners (Ireland, 2009; St. Denis, 2010; Vaught \& Castagno, 2008). They began to see how educational rhetoric and system practices perpetuated discourses of meritocracy and White privilege, in effect marginalizing the FNMI students that the rhetoric was supposed to help "fix.” Many participants worked 
through issues of White guilt (Aveling, 2006; Thompson, 2003) as they wrestled with their own privilege and complicit oppressions in the system, but they suggested that the collaborative approach to teaching in the institute and the open culture for dialogue based on respect helped them to voice their concerns, move beyond the guilt, and work towards strengthening their roles as allies (St. Denis, 2007).

The findings also aligned with Donald's (2009) work in that much more positive attitudes towards Indigenous peoples were created as educators had the opportunity to learn from and work with Indigenous leaders and educators in FNMI communities and/or organizations. They moved to a state of mindfulness of other perspectives and openness to new information that could dismantle stereotypes and build coalitions between nonFNMI and FNMI educators and leaders (Langer, 1997; St. Denis, 2007). Participants acknowledged the need, and offered examples, of their attempts to initiate programs, courses, or practices that were culturally relevant (Grande, 2004; Ladson-Billings, 1995), but also told us of the political, structural, interpersonal, and individual barriers that remained in the school system that constantly pushed back on attempts to decolonize education.

Finally, participants validated that our practice as instructors utilized prior experiences, cultural learning and knowledge, differentiated instruction, and relevant experiential learning experiences in community settings. They suggested that we had decentred expertise and allowed it to flourish and move fluidly within the learning community of students, guests, and instructors of the institute (Pewewardy \& Hammer, 2003).

As instructors, we learned the value of co-teaching for instructional purposes, for relationship development between instructors and students, and for creating a learning culture open to multiple perspectives. We found that designing our summer institute around what appeared to be four simple constructs (relevance, respect, reciprocity, and responsibility) engaged learners and built a learning culture where critical engagement with the risky notions of White privilege and decolonization could occur. We were affirmed in our belief that our different perspectives and life histories would allow us to bring different but valuable perspectives to the course, but neither of us was prepared for how responsive and appreciative our students were to our articulation and enactment of that. In addition, although the workload was high, we greatly enjoyed working with each other, with our guests, and with our students on our daily adventures that took place in interesting spaces rather than in a cold institutional university classroom.

The research process was similarly enjoyable, as we were able to engage with our past students in a comfortable and respectful sharing circle format that encouraged reflection and open dialogue. We are already in the planning stages for a second research project that will focus on the 2013 summer institute. Though we did our best to affirm the 4R's in 2013, we anticipate that we may find students more critical of the larger class size of the 2013 institute and the effects that could have had on relationality in particular.

Ultimately, supporting Aboriginal education involves changes in legislation, curricular, and the structures that define education. It also includes the training of those who are involved in the formal delivery of education services. Aboriginal educators and 
non-Aboriginal allies need to take a critical stance and recognize that every educational decision is a political one that has the potential to privilege and/or marginalize others. Educators and students need to be taught to utilize their voices to question, explore, and critique the status quo as a means of making changes that will provide a more equitable and realistic playing field for all students. We believe in the value of our summer institute and its potential impact for FNMI learners because we are targeting those in the systems who have the potential (and power) to make some of the changes that are necessary. The momentum of this summer institute appears to be growing; attitudes can be changed, and the time is ripe for system renewal. Not bad for an Anishanabe woman "from the bush" and a Saskatchewan "farm kid." 


\section{References}

Archibald, J. (2008). Indigenous storywork: Educating the heart, mind, body and spirit. Vancouver, BC: University of British Columbia Press.

Association of Canadian Deans of Education. (2010, June). Accord on Indigenous education. Accord presented at the Canadian Society for the Study of Education annual conference, Concordia University, Montreal, PQ.

Aveling, N. (2006). 'Hacking at our roots': Rearticulating White racial identity within the context of teacher education. Race Ethnicity and Education, 9(3), 261-274.

Battiste, M. (Ed.). (2000). Reclaiming Indigenous voice and vision. Vancouver, BC: University of British Columbia Press.

Battiste, M. (2002, October). Indigenous knowledge and pedagogy in First Nations education: A literature review with recommendations. Prepared for the National Working Group on Education and the Minister of Indian and Northern Affairs Canada.

Battiste, M. (2004, May). Animating sites of postcolonial education: Indigenous knowledge and humanities. Plenary Address made to the Canadian Society for the Study of Education annual conference, Winnipeg, MB. Retrieved from www.usask.ca/education/people/battistem/csse_battiste.html

Battiste, M., George, N.(P.), \& Anuik, J. (2009, May). Nourishing the learning spirit: A review of literature and promising practices. Paper presented at the annual conference of the Canadian Society for the Study of Education, Carleton University, Ottawa, ON.

Bell, D. (1991). Racism is here to stay: Now what? Harvard Law Journal, 35(79), 79-93.

Bogden, R., \& Biklen, S. (2007). Qualitative research for education: An introduction to theory and methods ( $5^{\text {th }}$ ed.). New York, NY: Pearson Publications Inc.

Brown, E. (1995). The tower of Babel: Bridging the divide between critical race theory and “mainstream” civil rights scholarship. Yale Law Review, 105, 513-547.

Chamberlain, J. (2000). From hand to mouth: The postcolonial politics of oral and written traditions. In M. Battiste (Ed.), Reclaiming Indigenous voice and vision (pp. 124141). Vancouver, BC: University of British Columbia Press.

Crenshaw, K., Gotanda, N., Peller, G., \& Thomas, K. (Eds.). (1995). Critical race theory: The key writings that informed the movement. New York, NY: New Press.

Dei, G.S. (1996). Anti-racism education: Theory and practice. Halifax, NS: Fernwood Publishing.

Delgado, R. (Ed.). (1995). Critical race theory: The cutting edge. Philadelphia: Temple University Press.

Dlamni, S. (2002). From the other side of the desk: Notes on teaching about race when racialized. Race Ethnicity and Education, 5(1), 51-66. 
Donald, D. (2009). The curricular problem of Indigenousness: Colonial frontier logics, teacher resistances, and the acknowledgement of ethical space. In J. Nahachewsky \& I. Johnston (Eds.), Beyond presentism: Re-imagining the historical, personal, and social places of curriculum (pp. 23-39). Rotterdam: Sense Publishers.

Freire, P. (1970). Pedgagogy of the oppressed. New York, NY: Herder and Herder.

Freire, P. (2003). Pedagogy of the oppressed: $30^{\text {th }}$ anniversary edition. New York, NY: Continuum.

Gay, G. (2000). Culturally responsive teaching: Theory, research and practice. New York, NY: Teachers College Press.

Grande, S. (2004). Red pedagogy: Native American social and political thought. Lanham, ML: Rowman \& Littlefield Publishers, Inc.

Grande, S. (2008). Red pedagogy. In N. Denzin, Y. Lincoln, \& L. Smith (Eds.), Handbook of critical and Indigenous methodologies (pp. 233-254). Thousand Oaks, CA: Sage Publications, Inc.

Guinier, L., \& Torres, S. (2002). The miner's canary: Enlisting race, resisting power and transforming democracy. Cambridge, MA: Harvard University Press.

Harris, C. (1993). Whiteness as property. Harvard Law Review, 106(8), 1707-1791.

Ireland, B. (2009). Moving from the head to the heart: Addressing the "Indian's Canada problem" in reclaiming the learning spirit-Aboriginal learners in education. Saskatoon, SK: University of Saskatchewan, Aboriginal Education Research Centre and the First Nations and Adult Higher Education Consortium, Calgary, AB. Retrieved from www.aerc.usask.ca

Johnson, R. (2002). Using data to close the achievement gap: How to measure equity in your schools. Thousand Oaks, CA: Corwin Press.

Kailin, J. (1994). Anti-racist staff development for teachers: Considerations of race, class and gender. Teaching and Teacher Education, 10, 169-184.

Kanu, Y. (2005). Teacher's perceptions of the integration of Aboriginal culture into the high school curriculum. Alberta Journal of Educational Research, 51(1), 50-68.

Kincheloe, J. (2003). Critical ontology: Visions of selfhood and curriculum. Journal of Curriculum Theorizing, 19(1), 47-64.

Kirkness, V., \& Barnhardt, R. (1991). First Nations and higher education: The four R'sRespect, relevance, reciprocity, responsibility. Journal of American Indian Education, 30(3). Retrieved from http://jaie.asu.edu/v30/V30S3fir.htm

Ladson-Billings, G. (1995). Toward a theory of culturally relevant pedagogy. American Educational Research Journal, 32(3), 465-491.

Ladson-Billings, G. (2005). The evolving role of critical race theory in educational scholarship. Race Ethnicity and Education, 8(1), 115-119.

Langer, E. (1997). The power of mindful learning. Reading, MS: Addison-Wesley. 
Levine-Radsky, C. (2000). The practice of Whiteness among teacher candidates. International Studies in Sociology of Education, 10(3), 263-284.

Little Bear, L. (2000). Jagged worldviews colliding. In M. Battiste (Ed.), Reclaiming voice and vision (pp. 77-84). Vancouver, BC: University of British Columbia Press.

Lowenstein, K. (2009). The work of the multicultural teacher educator: Reconceptualizing White teacher candidates as learners. Review of Educational Research, 79(1), 163-196.

McLaren, P. (2003). Life in schools: An introduction to critical pedagogy in the foundation of education ( $4^{\text {th }}$ ed.). Boston, MA: Allyn \& Bacon.

McNiff, J., \& Whitehead, J. (2006). All you need to know about action research. Thousand Oaks, CA: Sage Publications.

Morrison, K.A., Robbins, H.H., \& Rose, D.G. (2008). Culturally relevant pedagogy: A synthesis of classroom-based research. Equity \& Excellence in Education, 41(4), 433-452.

National Indian Brotherhood. (1972). Indian control of Indian education. Policy paper presented to the Minister of Indian Affairs and Northern Development. Ottawa, ON: National Indian Brotherhood.

Ottmann, J. (2010). Canada’s First Nations people: Ethnicity and leadership. In C.C. Wolhuter, \& H.J. Steyn (Eds.), Ethnicity and Educational Policies Education and Ethnicity: comparative perspectives/Education et ethnicité: perspectives compares (pp. 58-80). Potchefstroom, South Africa: Platinum Press.

Peden, S. (2011). Dancing with the elephant: Teacher education for the inclusion of First Nations, Métis and Inuit histories, worldviews and pedagogies. Unpublished doctoral dissertation, University of Manitoba.

Pewewardy, C., \& Hammer, P. (2003). Culturally responsive teaching for American Indian students. Charleston, WV: ERIC Clearinghouse on Rural and Small Schools.

Picower, B. (2009). The unexamined Whiteness of teaching: How White teachers maintain and enact dominant racial ideologies. Race Ethnicity and Education, 12(2), 197-215.

Royal Commission on Aboriginal Peoples (RCAP). (1996). Report of the Royal Commission on Aboriginal Peoples, (Vol. 3). Ottawa, ON: Canada Communications Group.

Schick, C., \& St. Denis, V. (2005). Troubling national discourses in anti-racist curricular planning. Canadian Journal of Education, 28(3), 295-317.

Shome, R. (1999). Whiteness and the politics of location. In T.K. Nakayama \& J.N. Martin (Eds.), Whiteness: The communication of social identity (pp. 107-128). Thousand Oaks, CA: Sage.

St. Denis, V. (2007). Aboriginal education and anti-racist education: Building alliances across cultural and racial identity. Canadian Journal of Education, 30(4), 10681092. 
St. Denis, V. (2010, Mar). A study of Aboriginal teachers' professional knowledge and experience in Canadian schools. Saskatoon, SK: Canadian Teachers’ Federation/Canadian Council on Learning.

St. Denis, V., \& Schick, C. (2003). What makes anti-racist pedagogy in teacher education difficult? Three popular ideological assumptions. Alberta Journal of Educational Research, 49(1), 55-69.

Canada, Indian and Northern Affairs. Statement of the Government of Canada on Indian Policy (The White Paper). (1969). Ottawa, ON: Queen’s Press. Retrieve from http://epe.lac-bac.gc.ca/100/200/301/inac-ainc/indian_policy-e/cp1969_e.pdf

Statistics Canada. (2006). Aboriginal identity population by age groups, median age and sex, 2006 Census counts, for Canada, provinces and territories, 2006 Census, highlight tables, Aboriginal peoples. Ottawa, ON: Industry Canada.

Stewart, S. (2009). One Indigenous academic's evolution: A personal narrative of Native health research and competing ways of knowing. First Peoples Child and Family Review, 4(1), 57-65.

Terwilliger, C. (2010, June). Mapping stories: Taking detours to challenge whiteness. Making Connections: Interdisciplinary Approaches to Cultural Diversity, 14-25. Retrieved from http://organizations.bloomu.edu/connect/spring2010/3\%mapping\%20Stories.pdf

Thompson, A. (2003). Tiffany, friend of people of color: White investments in antiracism. International Journal of Qualitative Studies in Education, 16(1), 7-29.

Vaught, S., \& Castagno, A. (2008). “I don’t think I'm a racist”: Critical race theory, teacher attitudes, and structural racism. Race Ethnicity and Education, 11(2), 95113.

Whitehead, K. (2007). Addressing social differences with prospective teachers who want “to make a difference.” Asia-Pacific Journal of Teacher Education, 35(4), 367-385.

Williams, L., \& Tanaka, M. (2007). Schalay’nung Sxwey’ga: Emerging cross-cultural pedagogy in the academy. Educational Insights, 11(3). Retrieved form http://www.ccfi.educ.ubc.ca/publication/insights/v11n03/articles/williams/williams. $\underline{\mathrm{html}}$

Wilson, S. (2008). Research is ceremony: Indigenous research methods. Halifax, NS: Fernwood Publishing.

Young, M. (2006). Pimastwin: Walking in a good way. Winnipeg, MB: Pemmican Publishers. 